\title{
Retailers' resilience strategies and their impacts on urban spaces in Turkey
}

\author{
Feyzan Erkip $^{\mathrm{a}, *}$, Ömür Kızılgün ${ }^{\mathrm{b}, 1}$, Guliz Mugan Akinci ${ }^{\mathrm{c}}$ \\ ${ }^{a}$ Bilkent University, Faculty of Art, Design and Architecture, 06800 Ankara, Turkey \\ ${ }^{\mathrm{b}}$ Portakal Çiçeği Sokak, 10/2, Aşağı Ayrancı, 06540 Ankara, Turkey

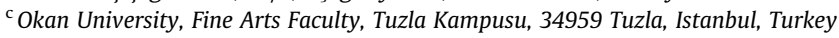

\section{A R T I C L E I N F O}

Article history:

Available online 5 January 2013

\section{Keywords:}

Retailing

Resilience strategies

Urban spaces

Turkey

\begin{abstract}
A B S T R A C T
Recent developments in the retail sector in Turkey have created a dynamic environment, with different resilience strategies of actors forming the sector providing a new context in which to discuss urban transformation. The developments have contributed to the public's awareness regarding multifaceted problems in the retail sector, many of which have a negative impact on urban space. Retailers, citizens and governing bodies variously contribute to this issue with different perceptions of and strategies on how to adapt to the changes. How these dynamics work and influence urban space in the Turkish context is the main focus of this research. A field survey in Ankara revealed that the resilience strategies of traditional retailers are reactive rather than proactive. This situation provides them with the flexibility to adapt themselves more quickly to the changes in the sector. However, as there is no holistic retail policy in Turkey, reactive strategies also result in unplanned use of urban space.
\end{abstract}

(c) 2012 Elsevier Ltd. All rights reserved.

\section{Introduction}

This paper addresses the impacts of globalization in the retail sector on the spatial organization of cities and urban planning in Turkey. The resilience strategies of various actors in retailing have led to changes in the spatial organization of many Turkish cities, which have experienced a rapid transformation in consumption practices and spaces in the last decades. In this article, the adaptive strategies of retailers of different scales are analyzed considering their impact on urban space.

Retail activities and consumption patterns are an important part of the spatial organization of contemporary urban spaces. Global trends in urbanization and the consumption-oriented organization of daily life have resulted in similarities between cities, often making shopping malls, hypermarkets and theme parks the core of the urban experience. These developments have caused a decrease in the use of public urban spaces, i.e. streets and plazas, in many cities.

These new forms of consumption spaces have some advantages with respect to physical features, such as the architecture, design and atmosphere generated in many shops. They are strategically located and designed to attract attention, fascinate and seduce individuals, i.e. consumers. More importantly, they change the ways consumer groups appropriate public space, influencing the norms of using such spaces. The new consumption spaces constitute a threat not only to the commercial aspects of traditional street shopping but also to socializing, strolling and browsing in

\footnotetext{
* Corresponding author.

E-mail address: feyzan@bilkent.edu.tr (F. Erkip).

1 Free lance Researcher.
}

public spaces as part of consumption-related leisure activities. There is much research on the impacts of globalization on local and small-scale retailers in the newly integrated markets (see, for example, da Rocha and Dib, 2002 on Brazil; D'Haese and van Huylenbroeck, 2005 on South Africa; Goldman, 2001 on China; Kalhan, 2007 on India). While Coe (2004) calls attention to the holistic and complex nature of retail internationalization, Dawson (2007) investigates the role of large retailers and their strategies in shaping this process. The conditions of the host country, which determine international investment, are also considered an important part of the debate. (See Goldman, 2001; Da Rocha and Dib, 2002 for the analysis of the relationship between the strategies of foreign investment and the behavior of host country retailers in Brazil and China, respectively.) Yet, research on the impacts of changes in retail markets of host countries on their urban land use is quite limited. In addition to the sector dynamics, a country's overall demographics and consumer profile are also influential in the development of the global consumption patterns.

Turkey seems to provide foreign capital investments with favorable conditions in the retail sector. Further, the urban population in Turkey is quite young compared to other European countries and density is quite high in urbanized areas. These facts create a dynamic use of urban spaces and the potential for the simultaneous use of globally designed consumption spaces (such as shopping malls) and traditional street retailers in urban centers, as well as for using open spaces such as parks for leisure activities and socializing. Recent research indicates that streets continue to be favorable shopping and socializing outlets for the young, lowerincome and more traditional segments of the population in Turkey (Ozuduru et al., in press). Still, small-scale retailing in Turkey has 
been struggling to compete with more organized and large retailers and shopping malls, and it seems that the contest is leaning toward the latter (see Erkip, Kizilgun, and Mugan, in press, for details).

The competition between new retail and consumption spaces and traditional ones has important impacts on urban public areas. In some cases, public spaces have been strategically developed to be consumption objects, and in other cases, modern retail spaces have replaced urban public spaces with no forethought (Erkip, 2005, 2003). Retail globalization affects shopping and consumption patterns in host countries (Coe, 2004), Turkey included. Because large retail developments offer a variety of uses of and meanings for consumption spaces, it is imperative to understand the resilience strategies developed by various retailers in the sector as a whole to be able to analyze their impact on urban environments. In the existing literature, this aspect lacks the attention it deserves.

\section{The resilience of urban systems}

A system's resilience was originally defined in relation to ecological balances, especially when the balance was threatened by a shock such as a natural disaster (Holling, 1973 cited in Simmie and Martin, 2010). Thus, resilience was seen as a measure of a system's persistence and its ability to absorb change and disturbance without changing its structure. The Resilience Alliance (2007:8) documents a marked ecological approach, and calls for cities that are able "to tolerate alteration before reorganizing around a new set of structures and processes". Cummings (2011) stresses the role of system complexity and identity in resilience dynamics. Urban areas are good examples of complex systems, which exhibit various levels of resilience when threatened by an outside force (Lang, 2011). Martin (2012) notes that their complexity goes far beyond that, and can be explained by the concept of regional resilience.

Researchers in social sciences, mainly in geography and economy, offer new points for debate on the shortcomings of the concept of resilience as defined ecologically (see Lang, 2011; Muller, 2011 for a detailed discussion). Simmie and Martin (2010), claiming that there is no universally accepted definition of resilience in economics and social sciences, reject 'equilibrist approaches' and argue that regions are continually changing and adapting to their economic environments instead of returning to a previous state. For them, resilience is a process, and stability is not a characteristic held by regions. Thus, they propose a 'revolutionary adaptive model' to understand how geographic regions adapt to disturbances through time. (See also Replacis, 2011 for a detailed discussion of the evolution of the concept of resilience.)

In this context, the resilience of an urban retail system is defined as the ability of different types of retailing to adapt to changes, crises or shocks that challenge the system's equilibrium without failing to perform its functions in a sustainable way (Replacis, 2011). The viability and vitality of an urban core can only be sustained through the resilience of different retailers. In some cases, the resilience of a retail area is the consequence of retailers' strategies, such as forming business organizations or garnering public subsidies, whereas in other cases, resilience is mostly a response to consumers' preferences. In this sense, Simmie and Martin (2010) cite Foster's (2007) distinction between spontaneous response and anticipated and prepared resilience, and thus their definition incorporates the planned response of actors in a process that requires deliberate action and investment. According to this approach, spontaneous resilience and planned resilience are two distinct possibilities that may occur during the process of adaptation. Spontaneous resilience is the typical reactive strategy that individual retailers undertake; it is essentially focused on outlets' retail activity. Planned resilience, however, requires the involvement of associations, municipalities and other public actors and is more comprehensive.
Muller (2011, p. 5) notes the inherent features that make some cities more resilient than others: "human perception, behavior and interaction, as well as decision-making, governance, and the ability to anticipate and plan for the future". In fact, the question of why some cities are more resilient is an important one for researchers (Coe and Wrigley, 2007; Martin, 2012). In recent decades, the process of retail decentralization and urban sprawl has contributed to the decline of city centers. Several policies and coalitions have attempted to address the resulting problems (Balsas, 2000); however, from a spatial point of view, links between retailing and urban development in different countries have not always followed similar trajectories. Spatial resilience is closely linked with the identity of the urban system (Cummings, 2010). In that respect, the Turkish urban structure requires deeper analysis to reveal the components that influence strategies of retail resilience and their spatial imprints.

\section{Recent transformations and resilience strategies in Turkey's retail sector}

\section{Recent transformations in the retail sector}

The recent changes in Turkey's retail sector due to changing economic policies and consumption patterns from the influence of global trends and long-lasting EU relationships have been discussed in earlier research in detail (See Erkip, 2005, 2003; Erkip et al., in press; Ozcan, 2000; Tokatli and ve Boyaci, 1998). The resulting changes in government policies and related legislation have mostly aided big capital to invest in shopping malls, gated communities and office towers to provide high-income groups a globally crafted life. Because of these developments, traditional forms of retail businesses and urban streets are experiencing a decline and need to attract customers in various new ways (see TMMOB-Chamber of Architects, 2011 for a detailed discussion on the developments and changes in the retail sector in Turkey).

Small and independent firms have dominated the retail sector in Turkey for longer than in most countries. Traditional open and closed bazaars in the Ottoman period, which had been replaced by convenience stores-grocers (bakkal), greengrocers (manav) and butchers (kasap) in the Republican period -have continued to be a major part of Turkish retailing in many cities and towns until today (Ozcan, 2000). The recent developments in the Turkish retail sector, however, have negatively influenced less organized or unorganized portions of the sector, resulting in a decrease in the number of small- and medium-scale shops. Between 1998 and 2008, the number of bakkal and small markets decreased from 223.091 to 195.184; the period between 1998 and 2006 witnessed an increase in the number of hypermarkets from 91 to 164 (Gayrimenkul Yatırım Ortaklığı Derneği (GYODER), 2009). Traditional sellers still hold over $60 \%$ of the retail market, but this majority is threatened (AMPD, 2010). According to Kompil and Çelik (2006):3, "open-air bazaars - with a wide variety of products, fresh fruits and vegetables - groceries and others - with their proximity and accessibility to home - continue attracting consumers". However, more organized (i.e., larger) sellers have been working hard to win a higher share of the market by providing a richer array of products and stores than their traditional counterparts. According to a recent report (Gayrimenkul Yatırım Ortaklığı Derneği (GYODER), 2011), the number of shopping malls in Turkey has reached 284, with a leasable area of 7.12 million square meters, and their retail sales have been increasing (Gayrimenkul Yatırım Ortaklığı Derneği (GYODER), 2011).

It seems that Western-style shopping malls and hypermarkets will continue to increase in popularity in Turkey (Economist 
Intelligence Unit (EIU), 2009). Yet, due to the impact of the last global crisis on Turkish consumers, which limited demand, discount stores and outlets are expected to increase their shares (Economist Intelligence Unit (EIU), 2009). According to a recent report by Jones Lang LaSalle (2011a), outlet centers constitute $15.6 \%$ of organized retailing, where neighborhood malls dominate with $52.6 \%$ in Turkey. Regional and super-regional centers take $27.5 \%$ of the market. The remaining percentages belong to lifestyle and theme centers. Although the number of retail centers and shopping malls has been increasing, the retail sector's structure is still highly fragmented, and a radical change is not expected in the near future.

There is a continuous struggle between domestic capital (mainly represented by traditional and small-scale retailers) and corporate capital (represented by organized retail investments). Under these conditions, corporate capital (domestic and foreign) has been a powerful actor in the economy. However, the market is still dominated by domestic capital over the entire country. The main indicators of this struggle are recent constructions of luxury malls in big cities on the one hand, and on the other hand, the resistance of small shops, street shopping and open bazaars and the smaller, lessimpressive shopping centers of minor Anatolian cities. Under this dual structure and uncertainties, state interventions are few and do little to guide the development of the sector (Erkip et al., in press). For these reasons, different resilience strategies of retailers of various scales determine the sector's composition.

A law regarding supermarkets, hypermarkets and chain stores (prepared in 2004; not yet approved) would apply to stores of 5000 square meters or more and demand that such large-scale businesses relocate or be built beyond city limits. The aim of the law is threefold: (i) considering consumer rights, (ii) providing for modern urbanization and (iii) balancing the competition between various segments of the retail sector. The first aim concerns product quality, price stability, packing and hygienic conditions. In terms of the second aim, the law would require strategic urban and environmental impact assessments to evaluate new demands for organized retail areas. With the third aim, existing small- and medium-sized enterprises would have to be considered in the sitting of a large retail store, with location density and working hours regulated accordingly. There has been ongoing discussion about the necessity for large stores to move outside city limits; this regulation is viewed as a protective measure in favor of small shops in city centers and the big retailers are against it.

In Turkey, municipalities and governorships are responsible for the development and implementation of urban plans; they also supervise the building and administration of shopping malls in their regions. In certain areas, shopping malls are located so close together that their catchment areas overlap and create serious competition. Densely located shopping malls also have negative effects on urban transportation. Capital investors decide on a subjective basis where to build these huge structures and often pressure local authorities to change land-use plans accordingly (Erkip et al., in press). Such developments create traffic problems and congestion in city centers and are an imbalanced use of urban land.

Many small- and medium-sized retailers have been experiencing declines in their businesses, but specific reasons for why are unclear to them. Decreases in demand may be due to a drop in the number of urban-core residents, and/or a reduction in those residents' incomes, a reduction in the number of people working in the neighborhood and/or because of new forms of consumption available. Turkish retailers often cite lower purchasing power caused by economic crises and increases in unemployment rates as a reason for diminishing business returns (Replacis, 2011). With no comprehensive retail policy, retailers of all levels and scales may feel insecure. The above-noted aspects of the Turkish retail sector need to be analyzed in their specific contexts to observe how different retailers experience and react to changes.

\section{Resilience strategies of different retailers}

In Turkey, small-and medium-sized retailers' resilience strategies tend to be reactive. Such strategies can be at different levels, depending on the scale and adaptive capacity of retailers as well as on their links with the more organized segments of the sector. Small-scale traditional and more organized retailers with large capital follow different routes to resilience, yet there are common strategies that would smooth the road toward a more organized retailing environment in general.

Improved sanitation and longer service hours are the resilience forms mostly adopted by street vendors such as bread vendors, second-hand goods vendors and lottery ticket vendors (simitci, eskici and piyangocu, respectively). Street vendors are an indispensable component of retailing in Turkey. Their organizational potential is weak, yet they have adapted to decreased demand by improving their food-preparation standards, using better and cleaner service stands (in some cases provided by the municipality) and selling their products at night to prevent competition from more organized retailers. Kalhan (2007) points out the intensifying competition between organized corporate and independent informal retailers for urban space in India. In Turkey, informal retailers lost this battle and those who remain active try to adopt strategies that help them to be or look more organized and modern. Small grocery stores have adapted also by improving sanitation and by offering home delivery services throughout their working hours. This group of retailers practices traditional values (neighborliness and mutual trust and tolerance) and informal business transactions (negotiation, bargaining and buying on tick), although these types of attitudes and customs are decreasing in this sector, as well as in society overall.

Changing a shop's image and inventory by adding new products or changing target groups are also among this segment's frequently applied strategies. There are many examples of retailers adapting by aiming at higher-income or lower-income targets, either by improving their quality of merchandise, displays and services or by selling lower-quality goods. Publicity and personalized advertising strategies that increasingly rely on the Internet, SMS messages and e-mail are likewise being included in communication strategies. Such retailers might offer discounts on certain articles on special days and gifts on celebration days (Mother's Day, Women's Day, etc.), following the examples of large retailers.

Organizing through chains is another strategy for some small and traditional distributors to compete with the more organized segments of the sector and to survive in a more global retail environment. This process generally requires the involvement of large capital, and is thus not an option for many retailers. The most recent example in Turkey is Fayda, inaugurated in 2008. It brought together 73 local-market chains with 852 shops in 23 cities (Fayda, 2012). The discount market chain BIM A.S. has more than 2665 stores across Turkey and is growing fast, with a plan to open about 300 stores per year (Deloitte, 2010). SOK is an example of large domestic capital (Migros formed SOK, a discount brand that it recently sold to another market leader, the Ulker Group (Sabah, June $8,2011)$ ).

The increasing number of shopping malls in Turkey has required architects and managers to be more creative in the design and image of the structure itself, in addition to product variety and quality. Because such spaces also serve as leisure sites, with coffee shops, restaurants, movie theatres and theme parks, the level and quality of services provided are important aspects of their presentation. In Turkey, these new-generation malls have won many awards for their distinct architectural and design features (see Multi Corporation, 2011 for examples of such sites), proposing a new lifestyle with multinational capital. The first-generation 
malls of the1980s have suffered from the competition, and declined.

The number of discount outlets is also on the rise in Turkey, given that many offer quality products - even brand names cheaper than their higher-end counterparts. Such stores are usu- ally located in city centers, sometimes very close to malls, and they contribute to the competition between organized retailers. According to the International Council of Shopping Centers (ICSC) (2010):3 “. . .in Turkey, 'quasi outlet centers' are being developed consisting of hybrid centers offering outlet shopping alongside a

Table 1

Different actors and resilience strategies in the retail sector in Turkey. Source: adapted from Erkip, Kizilgun and Mugan (2011).

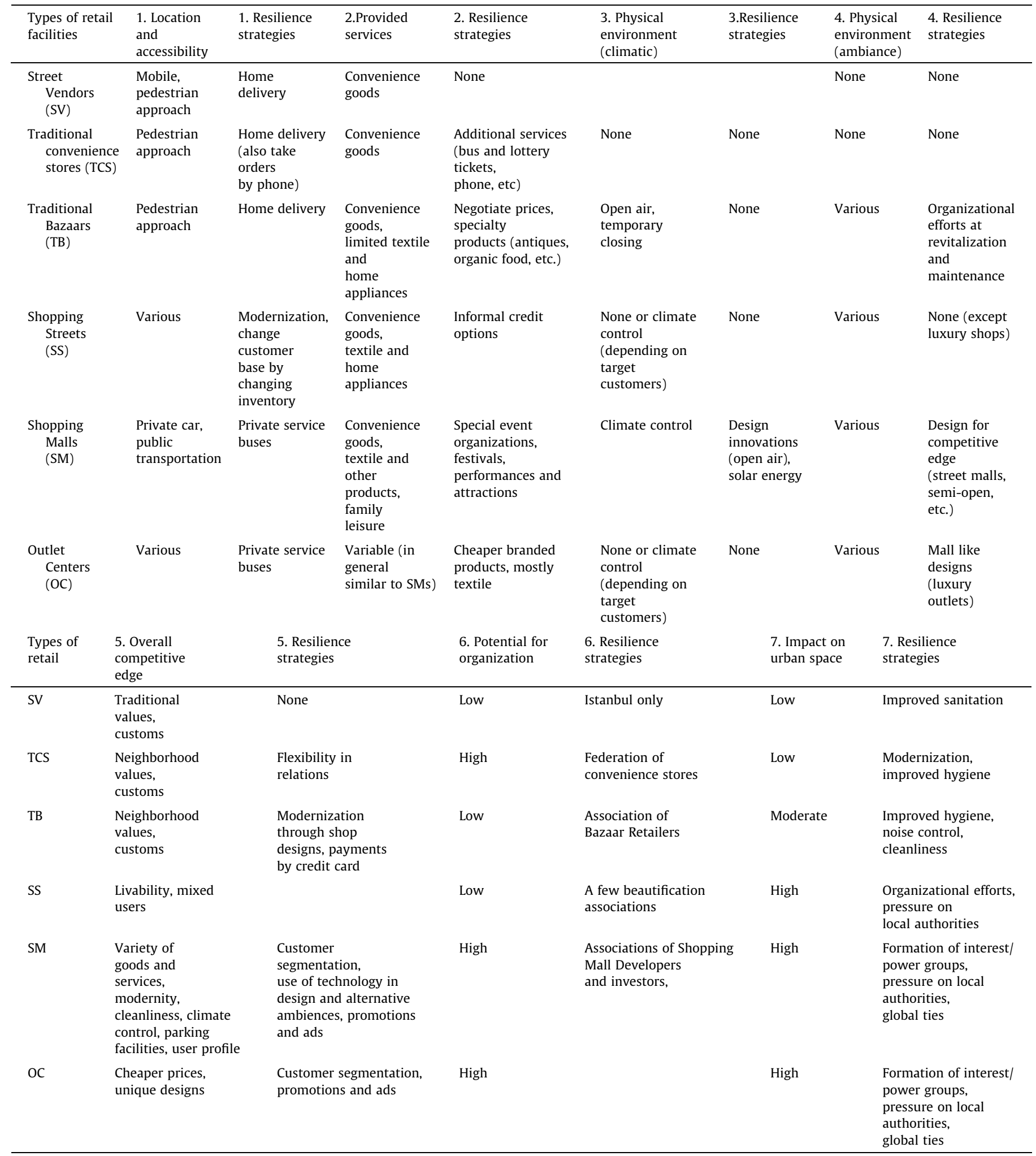


hypermarket and leisure offer and with full price shopping malls all in a quality environment. This is an interesting cultural variation".

More-organized segments of the retail sector are more successful at coping with change than less-organized segments, as expected; they anticipate it with greater accuracy and are thus able to better prepare for it. In Turkey, shopping malls and outlet centers have formed groups and associations that pressure local authorities to change development plans. This is a problem for the planned development of city and public spaces (for a more detailed discussion on this issue, see Erkip et al., in press). See Table 1 for the resilience strategies of all segments of Turkey's retail sector.

Utilizing the general outlines of resilience strategies, we analyzed the viewpoints of retailers and consumers through a field survey in Ankara to determine their perceptions of change in retailing and discuss adaptation strategies, considering their implications for urban policies. The discussion and findings are given in the following section.

\section{The field survey}

Turkey's large cities reflect the vivid character of the country's retail sector and provide their citizens with a variety of shopping options. With its numerous shopping districts consisting of traditional and modern/global retailers, Ankara, the capital city, is one of the most appropriate sites for studying changes in the retail sector and consumer preferences with its multi-central character. At the time of this research, it was the city with the highest shopping mall area per capita, which makes it a good case for analyzing the change in consumer preferences. For this study, we selected a traditional street (Kucukesat Street), an adjacent high-street (Tunali Hilmi Street) and a first-generation shopping mall (Karum) located at one end of the high-street (see Appendix, Fig. 1 for the map of the study field). This area has a rich retail mix, but it was assumed that the shopping mall, evolving towards providing consumers with more alternatives in terms of product variety and design, would be the most popular shopping choice, particularly for Ankara's middle- and high-income citizens (see Fig. 1 below for the distribution of retailing in the survey area).

The research consisted of interviews with selected retailers on both streets and one of the managers of the shopping mall. For the interviews, the type of retail business was taken as a basis to be able to cover differences between retailers; thus, the results were not expected to reflect the full variety in the sector.

Twenty-seven retailers were interviewed, most of them male (78\%) with a high education rate (59\% had higher education). About half the retailers were tenants, one-third were owners and the remaining were employees. The number of employees in a store varied from 1 to 13 , with an average of 4.5 . The age range was between 20 and 67, the time worked in the sector was between 2 and 41 years and the time worked on the same street was between 1 and 41 years. These numbers indicate that business on both streets has been quite stable and thus can provide important observations on the changes in the retail environment in relation to the businesses and the district.

The most commonly used resilience strategies were product specialization, increased sanitation and standardization, offering promotions, discounts and longer opening hours and providing additional services such as home delivery. Retailers' problems,

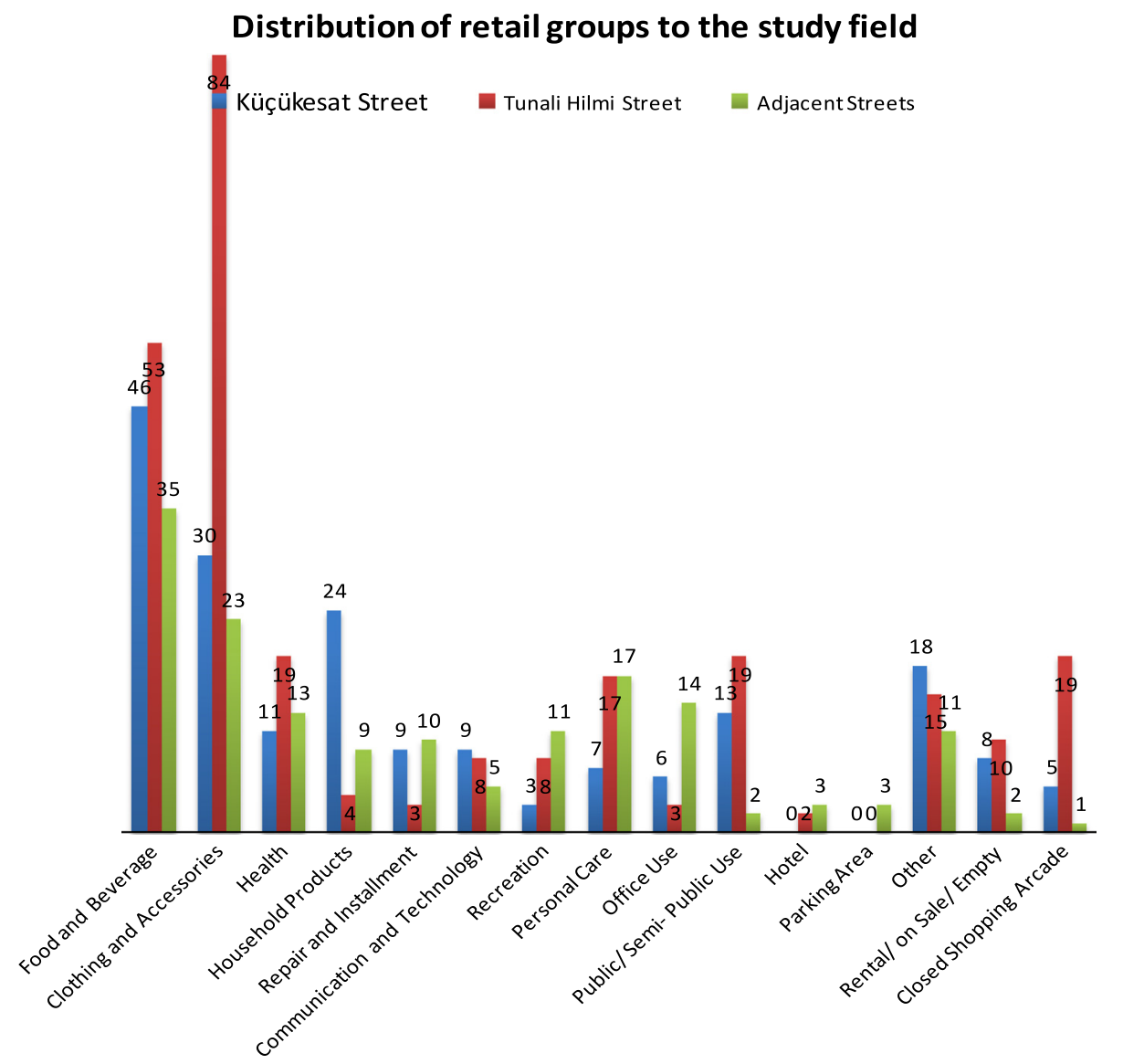

Fig. 1. Distribution of retail groups in the study field (documented by the project team). 
Table 2

Interview findings: problems and suggestions.

\begin{tabular}{|c|c|}
\hline Problems & Strategies and suggestions \\
\hline $\begin{array}{l}\text { Heavy vehicular traffic } \\
\text { - Lack of sufficient and well-maintained pedestrian pathways and } \\
\text { sidewalks } \\
\text { - Traffic congestion }\end{array}$ & $\begin{array}{l}\text { State and local government authorities should undertake more responsibility and } \\
\text { increase infrastructure investment }\end{array}$ \\
\hline One-way traffic flow (disadvantageous for adverse side of the street) & Return to two-way traffic flow \\
\hline Insufficient parking facilities & Allocation of parking areas by the municipality \\
\hline $\begin{array}{l}\text { Political struggles between two layers of local governments (district and } \\
\text { Greater Ankara Municipality) }\end{array}$ & Resolve disagreements to improve street services \\
\hline $\begin{array}{l}\text { - } \quad \text { Insufficient municipal services } \\
\text { - } \quad \text { Insufficient maintenance and infrastructure } \\
\text { - } \quad \text { Distorted and broken sidewalks and pavements } \\
\text { - } \quad \text { Insufficient number of trash cans and cleaning services }\end{array}$ & Coordinate street organizations better \\
\hline $\begin{array}{l}\text { Uncontrolled increase in the number of shops in the area } \\
\text { Imbalances in the retail mix }\end{array}$ & Increase control over the number of and location of shops on the street \\
\hline Increase in the number of shopping malls & $\begin{array}{l}\text { Support neighborhood relations } \\
\text { Control retail mix on the street } \\
\text { Transform street into an attraction center } \\
\text { Relocate malls and supermarkets outside the city center }\end{array}$ \\
\hline Insufficient variety of goods and decreases in the number of shops & $\begin{array}{l}\text { Attract brand names to the street } \\
\text { Increase the number of cafes and restaurants } \\
\text { Create an open-air mall }\end{array}$ \\
\hline
\end{tabular}

however, were not restricted to the growth of large retail developments; respondents also cited a lack of municipal services such as infrastructure and street maintenance and upkeep as a major problem (see Table 2 for problems and retailers' suggestions for improvement). Further, there were differences in complaints according to the type and scale of retail businesses; for example the haberdasher, the owner of the furniture repair shop and the tailor in the sample group expressed that they were not influenced by shopping mall developments due to the loyalty of their customers and the nature of their businesses. The owner of the convenience store stated that his sales were threatened by supermarket openings in the neighborhood, not by shopping malls.

One major complaint concerned traffic conditions. Especially after the streets became one-way arteries a few years ago, vehicle traffic has become more congested and has made pedestrian access and use more difficult. This change is disadvantageous for shops on the adverse side of the road, especially when people park their cars curbside. When this problem developed, retailers expected the local government to solve it; a return to two-way traffic was the favored solution. Regarding the retail mix on the street, respondents stated that unplanned development has harmed their businesses, with shopping mall development seen as partly responsible for the drop. As retailers did not feel that their problems were being addressed by existing organizations, they suggested solutions to make their streets more attractive, including better maintenance and services by the municipality and more active local organizations. Although there are non-profit organizations formed by retailers and citizens of both streets, the retailers did not seem to believe that their problems were being properly addressed. Respondents also noted that problems between the two layers of local government-the district and the Greater Municipality-have caused conflicts and bottlenecks in the provision of services. Some retailers noted the positive role traditional values (such as friendly relations with their neighbors) play in their businesses, yet they also noted that these values have been losing importance for many citizens.

The shopping mall administration seems to have experienced problems with tenants and was suffering from competition with new and more luxurious shopping malls. It is interesting to note that the surveyed mall, which opened in 1989, has been operating according to a law for flat ownership, making collective man-
Table 3

Socio-demographic information about the sample group.

\begin{tabular}{lll}
\hline & Frequency (\#) & Percentage (\%) \\
\hline Gender & & \\
Male & 55 & 36.7 \\
Female & 95 & 63.3 \\
Total & 150 & 100.0 \\
Age & & \\
15-25 & 57 & 38 \\
$26-30$ & 34 & 22.7 \\
$31-40$ & 36 & 24.0 \\
$41+$ & 23 & 15.3 \\
Total & 150 & 100 \\
Education level & & \\
High school graduate & 16 & 10.7 \\
University graduate & 93 & 62.0 \\
Masters degree & 41 & 27.3 \\
Total & 150 & 100.0 \\
Income level & & \\
Low & 4 & 2.7 \\
Middle & 116 & 77.3 \\
High & 30 & 20.0 \\
Total & 150 & 100.0 \\
\hline
\end{tabular}

agement and identity formation impossible. Because of this, the mall management experiences difficulties also with shop owners who want to determine the level of rent and keep their shops vacant until they find a tenant willing to pay it. Thus, despite its central location with pedestrian access, it suffers from low occupancy rates and has lost its appeal for investors and customers. Its main resilience strategies seem to be to specialize its products and reduce the rents. Brand name stores such as Lacoste and BOFF Drugstore did not seem to be influenced as much as other shops, however, according to the interviews with the owners.

\section{Questionnaire results}

As a second step, we surveyed 150 people in a popular café on the high-street through a detailed questionnaire. The sample for the questionnaire was purposive to reach citizens who may be 
Table 4

Usage patterns.

\begin{tabular}{|c|c|c|}
\hline & Frequency (\#) & Percentage (\%) \\
\hline \multicolumn{3}{|c|}{ Duration of visiting THS in years } \\
\hline Less than 1 year & 1 & 0.7 \\
\hline $1-3$ years & 10 & 6.7 \\
\hline $3-5$ years & 15 & 10.0 \\
\hline $5-10$ years & 42 & 28.0 \\
\hline More than 10 years & 82 & 54.7 \\
\hline Total & 150 & 100 \\
\hline \multicolumn{3}{|l|}{ Frequency of visits } \\
\hline Several times a week & 74 & 49.3 \\
\hline Once a week & 39 & 26.0 \\
\hline Once or twice a month & 37 & 24.7 \\
\hline Total & 150 & 100 \\
\hline \multicolumn{3}{|l|}{ Day of visit } \\
\hline Saturday & 121 & 29.2 \\
\hline Sunday & 51 & 12.3 \\
\hline Monday & 40 & 9.6 \\
\hline Tuesday & 39 & 9.4 \\
\hline Wednesday & 52 & 12.5 \\
\hline Thursday & 42 & 10.1 \\
\hline Friday & 70 & 16.8 \\
\hline Total & 415 & 100 \\
\hline \multicolumn{3}{|l|}{ Time of visit } \\
\hline $8.00-11.00 \mathrm{am}$ & 9 & 4.1 \\
\hline $11.00 \mathrm{am}-2.00 \mathrm{pm}$ & 23 & 10.5 \\
\hline $2.00-5.00 \mathrm{pm}$ & 71 & 32.3 \\
\hline $5.00-8.00 \mathrm{pm}$ & 74 & 33.6 \\
\hline After $8.00 \mathrm{pm}$ & 30 & 13.6 \\
\hline Other & 13 & 5.9 \\
\hline Total & 220 & 100 \\
\hline \multicolumn{3}{|l|}{ Average duration of visits } \\
\hline $30 \mathrm{~min}-1 \mathrm{~h}$ & 3 & 2.0 \\
\hline $1-3 \mathrm{~h}$ & 64 & 43.5 \\
\hline $3-5 h$ & 57 & 38.8 \\
\hline $5 \mathrm{~h}$ or more & 23 & 15.6 \\
\hline Total & 147 & 100 \\
\hline
\end{tabular}

Table 5

The purpose of visit and alternative shopping sites.

\begin{tabular}{lll}
\hline & Frequency (\#) & Percentage (\%) \\
\hline The purpose of visit & & \\
Meeting friends & 7 & 2.5 \\
Hanging out & 81 & 29.2 \\
Cafés & 71 & 25.6 \\
Shopping & 47 & 17.0 \\
Theatres, cinemas, exhibitions & 8 & 2.9 \\
Walking and window shopping & 32 & 11.6 \\
Business & 22 & 7.9 \\
Other & 9 & 3.2 \\
Total & 277 & 100.0 \\
Alternative shopping sites & & \\
Neighborhood grocery & 14 & 7.7 \\
Neighborhood supermarket & 38 & 20.8 \\
Shopping mall & 121 & 66.1 \\
Open bazaar & 6 & 3.3 \\
Other & 4 & 2.2 \\
Total & 183 & 100.0 \\
\hline
\end{tabular}

more affected by the changes in the sector and to ensure high participation in the survey. Although the sample has an upward bias in terms of education and income levels, this did not create a problem, as this group of citizens constitutes the most-frequent patrons of the high-street.

We evaluated the questionnaire results in terms of demographics, education and income, as well as the frequency of, duration of and reasons for visiting the street (see Tables 3 and 4).
Among the respondents, the numbers of females and young people were high. More than $60 \%$ of the sample group was female and more than $60 \%$ was under 30 . More than $80 \%$ had higher education, a rate much higher than Turkey's education rate overall, and even Ankara's average. This statistic likely results from the characteristics of the selected site, as mentioned earlier. This aspect contributed positively to the survey, as almost everybody who was asked volunteered to participate and gave additional information about related topics. Mainly, we found that almost half the sample group visited the street a few times a week and more than $80 \%$ spent between 1 and $5 \mathrm{~h}$ there, which indicated that this street is a popular destination for this group of citizens. The area was dominantly used for browsing and café visits, with shopping taking third place among the reasons for visiting the street (see Table 5 for the purposes of visiting the street).

The most common complaint about the street was traffic conditions, followed by lack of maintenance. The street's sanitation conditions were acceptable to many consumers. Greenery was found to be sufficient despite the lack of greenery on the street itself; this finding may be due to a nearby public park. Security was also evaluated as sufficient, which was an expected result for Ankara, as it is considered a safe metropolis. The retail mix was also found to be well balanced. The most striking finding was the perception of shopping mall development. Although many people perceived such development negatively, the dominant site for shopping appeared to be the malls in general (see Table 5 for other shopping sites). This shows an apparent contradiction between the attitude and behavior of the respondents.

The retailers' and residents' organization (Kavakliderem Dernegi one of the few active ones in Ankara) is not influential due to a lack of interest; the consumer questionnaire revealed that most citizens were either not aware of or were not willing to participate in the organization.

To evaluate the responses to the user questionnaire, we used correlations, chi-square analysis and factor analysis. Among the demographic characteristics, only gender appeared to have an impact on frequency of visits and perception of the retail mix on the street. Females visited the streets more often and were less satisfied with the mix. As the result of the factor analysis, we developed three indices:

(1) Satisfaction: This index appeared to be correlated only with the user profiles of the high street and the shopping mall openings in Ankara. Respondents who thought that the user profile of the street had changed over the years were less satisfied. Those who were positive about shopping malls were less satisfied. Those who are indifferent about mall openings were the most satisfied with Tunali Hilmi Street.

(2) Support: This index seemed to be related with frequency of visits, garnering the highest support from everyday users. This finding may be expected; however, it is surprising that the duration in years of visiting the high street and the average duration of visits were not correlated with support.

(3) Habits and attachment: This index was correlated only with the frequency of visits, with the highest level of attachment by everyday users. We did not find the expected relations between habits and the duration of visiting the high street in years and the average duration of visits.

The purpose for using the street did not appear to be related with any of the indices. Similarly, the specific character of the street did not seem influential.

In terms of the relations between indices, we found that satisfaction and support were positively correlated; habits and support 
were negatively, yet insignificantly, correlated, whereas satisfaction and habits were negatively and significantly correlated.

The role of 'emotional reasons' for attachment to spaces, such as habits, customs and familiarity, should not be neglected when dealing with usage patterns. Where these dimensions are concerned, questions of identity, familiar characteristics and even traditional aspects such as bargaining (haggling/discussing price), as is the case in Ankara, are important. However, this observation did not appear to be dominant in this study, probably because of the sample characteristics. This might be seen as a limitation of the survey as the sample group was not representative of Ankara citizens, but it should also be noted that with the extensive modernization of retailing such emotional aspects of consumer behavior have been disappearing in general.

\section{The impact on urban space and policy proposals}

The field survey in Ankara indicated that traffic congestion and insufficient parking are the dominant complaints of citizens in the city center. Retailers' complaints related to this issue are that oneway traffic on both streets causes retailers on the adverse side to lose customers and that the one-way traffic has made these two streets major arteries, making pedestrian access more difficult. Curbside parking, which is common in Ankara, contributes to this problem. Further, due to the traffic load, many illegal situations occur that are overlooked by police. Recently, to make money, the Greater Municipality began charging fees for parking curbside instead of regulating traffic flow and providing sufficient parking spaces. Municipal parking officers encourage drivers to park regardless of whether they are blocking pedestrian access. Further, the recent smoking ban in restaurants, effective since July 2009, has caused street and sidewalk congestion around the doors of cafés and restaurants. This situation blocks pedestrian traffic especially in the spring and summer, when more people are on the streets. There is also a lack of control regarding street-level shops expanding their wares onto the sidewalks. Further, considering the maintenance problems, it is apparent that pedestrian use of the streets is not well supported by local authorities, as mentioned by the retailers and citizens during the field study. In that particular case, there have been conflicts between the district-Cankayaand the Greater Ankara Municipality, as opposing political parties have been in power for a long time. This is believed to be one of the causes of insufficient services provided for that area.

Shopping mall development has had a negative influence on the demand for street retailers. As the field survey indicates, citizens mostly prefer malls for shopping. Yet, the impact of shopping malls is expected to be higher on the high-end of retailing and high streets. Other street retailing is facing decline under the threat of outlet centers and supermarkets. Retailers participating in the field survey blame shopping malls for decreasing their sales and for changing citizens' shopping habits. This development also decreases the use of open public spaces and streets, which should concern municipalities and citizens alike.

The unplanned development of new shopping forms in the city causes traffic problems, unjust competition among retailers and slates valuable urban land only for commercial development. Retailers' and consumers' impacts on Ankara's urban spaces indicate that many problems stem from a lack of consistent and holistic retail planning. It seems that different actors in the system apply spontaneous resilience strategies to sustain the balance or cope with changes. Haphazard development and transformation of retailing and related land use is a threat to the viability of the city center and to small-scale businesses, which are more vulnerable to impacts of change.

\section{Concluding remarks}

This aim of this research was to analyze various retailer strategies in Ankara, the capital city of Turkey, in a rapidly changing period of globalization. We conducted a survey to document resilience strategies of retailers and consumption patterns of citizens considering the need to understand the implications of retail transformations for urban and spatial planning.

The retail sector in Turkey nourishes and acts as a prime motivator of the economy. Deloitte (2010) notes Turkey's potential for further retail investment. Jones Lang LaSalle (2011b) evaluates 2010 as a positive year in Turkey due to an increase in retail expenditures. According to Deloitte (2012), the total size of the retail sector is expected to reach 313 billion USD in 2012. This observation was verified by GYODER (2011), indicating that consumption expenditures have increased compared to the last 2 years. Sales realized in shopping malls have also increased in the last 2 years. Apparently, the retail sector has been a prime mover of the economy in recent years; and when retailers of different scales are properly located and integrated within urban development plans, with good connections to other land uses, the retail sector is an important agent in maintaining the viability of urban areas and city life.

Creative retailing strategies contain important clues for policy development in Turkey and could be utilized for spatial planning and organization in many cities if municipalities are willing. Such examples include a more hygienic environment for street vendors when local authorities provide them with closed carts to contain food products. Such changes are often a result of EU negotiations, as EU provisions require governments to improve the unhealthy conditions of food sellers. It is imperative for state officials to sustain a balance between retailers of various scales to sustain the viability of city centers and public spaces. In this manner, the traditional aspects of urban life can be preserved. Small grocers are the core of neighborhood relations and street watching (this sort of security and surveillance can be viewed as positive or negative) and are needed to sustain the informal relations of local communities; there are people who remain faithful to their former neighborhood stores even after moving to other areas of the city. Such stores may still need to update themselves to compete with more modern and more organized retail forms, yet this is possible with the help of government subsidies. Having a shopping alternative in one's neighborhood decreases the need for transportation and helps make cities more sustainable.

Lack of sufficient public transportation is part of the traffic problem in Turkish cities, especially in large ones. Locating shopping malls and large stores on the outskirts works best with the aid of public transportation; Ankara's proposed subway has been under construction for a long time; the first phase of construction started in the 1980s. Private and organized retailers, shopping malls and outlets now provide their customers with free bus services from and to the city center. This is a good example of organized retailers' resilience strategies and may inspire local governments to consider similar solutions.

The spatial organization of contemporary cities is inevitably linked with consumption practices, either in the form of shopping or in browsing as a leisure activity. Open shopping arcades and open-air festivals are tools to keep people outside when the weather permits; this is particularly important for cities with long periods of mild climate. It seems that Turkish people utilize this opportunity with extensive use of the streets as well as the new consumption sites (Ozuduru et al., in press). Streets and open public spaces could be enhanced by proper maintenance and by considering urban design and aesthetic qualities. This subject is beyond the focus of this paper, yet it should be studied in the Turk- 
ish context considering the impact of the physical environment on citizens' behavior in public spaces.

Public authorities must undertake more responsibility in reducing urban retail areas' vulnerabilities. A holistic approach is required to streamline retail policies with relevant issues such as land use and traffic planning, defining strategies for inviting the participation of public organizations and citizens, keeping public spaces of the city attractive through continuous upgrading and maintenance and supporting retailers and their associations with financial subsidies (Replacis, 2011).

Turkish retailing has been adapting to the standards and formats of EU countries for some time, and this process may be an opportunity to learn from other countries' experiences in spatial transformations and policies (Erkip, Kizilgun and Mugan, 2011). However, Turkish governing bodies responsible for space planning do not seem to be aware of this opportunity as much as retailers and investors are. Further, the lack of official records that we observed in this research indicates the need for a system to gather systematic data on retail developments, turnover and vacancy rates, which is a starting point for planned intervention and guidance and is the only way to track changes in the sector. The next step would be detailed surveys on consumer demand from and satisfaction with the retail distribution as well as the physical environment and design. Retailers, citizens and their organizations are stakeholders in this process and important sources of information. How to encourage actors to become more proactive must be explored by holistic governance that provides support for the process. Traditionally, Turkish administrations do not often include civil-society organizations in the decision-making process or are not involved in public-private undertakings. It is time, before urban centers become empty storefronts and vacant apartments, for municipalities and non-profit retail and citizens' organizations to take part in a new understanding to develop and implement revitalization projects to get citizens into the streets and spaces of urban centers.

\section{Acknowledgments}

This research was a part of an Urban-Net project, which was conducted by the researchers from France, Sweden, Portugal and Turkey between 2009-2011. We are grateful to colleagues who participated in this project for their contribution to our knowledge on retail planning in different European countries.

\section{Appendix A. Supplementary material}

Supplementary data associated with this article can be found, in the online version, at http://dx.doi.org/10.1016/j.cities.2012.12.003.

\section{References}

AMPD and PWC (2010). Parlayan Ylldı: Perakende Sektörünün Türk Ekonomisine Etkileri. <http://www.ampd.org>.

Balsas, C. J. L. (2000). City center revitalization in Portugal: Lessons from two medium size cities. Cities, 17(1), 19-31.

Coe, N. (2004). The internationalisation/globalisation of retailing: Towards an Economic - geographical research agenda. Environment and Planning A, 36, 1571-1594.

Coe, N. M., \& Wrigley, N. (2007). Host economy impacts of transnational retail: The research agenda. Journal of Economic Geography, 7, 341-371.
Cummings, G. S. (2011). Spatial resilience in social ecological systems. Dordrecht: Springer.

Da Rocha, A., \& Dib, L. A. (2002). The Entry of Wal-Mart in Brazil and the Competitive Responses of Multinational and Domestic Firms. International Journal of Retail \& Distribution Management, 30(1), 61-73.

Dawson, J. A. (2007). Scoping and conceptualising retailer internationalisation. Journal of Economic Geography, 7, 373-397.

Deloitte and Planet Retail (2010). Hidden Heroes Emerging Retail Markets Beyond China (pp. 33-36). <http://www.deloitte.com>.

Deloitte (2012). Retail sector update, corporate finance, June $2012<$ <ttp:// www.deloitte.com/view/en_TR/tr/index.htm>.

D'Haese, M., \& van Huylenbroeck, G. (2005). The rise of supermarkets and changing expenditure patterns of poor rural households case study in the Transkei Area, South Africa. Food Policy, 30, 97-113.

Economist Intelligence Unit (EIU) (2009). Industry Report - Consumer Goods and Retail Turkey, March.

Erkip, F. (2003). The shopping mall as an emergent public space in Turkey. Environment and Planning A, 35, 1073-1093.

Erkip, F. (2005). The rise of the shopping mall in Turkey: The use and appeal of a mall in Ankara. Cities, 22, 89-108.

Erkip, F., Kizilgun, O., Mugan, G. (2011). Kentlerin Sürdürebilirliği için Perakende Sektörünün Planlanması, The report prepared for the Replacis project by the Turkish team.

Erkip, F., Kizilgun, O., Mugan, G. (in press). The role of retailing in urban sustainability: The Turkish case, European urban and regional studies, first published on March 13, 2012 as doi: 10.1177/0969776411434846.

Fayda, A.S. (2012) <http://www.faydaas.com.tr>

Goldman, A. (2001). The transfer of retail formats into developing economies: The example of China. Journal of Retailing, 77, 221-242.

Gayrimenkul Yatırım Ortaklığı Derneği (GYODER) (2009). Türkiye gayrimenkul sektörü temel göstergeleri 2008. İstanbul GYODER.

Gayrimenkul Yatırım Ortaklı̆̆ı Derneği (GYODER) (2011). Türkiye ve Dünya Gayrimenkul Sektör Raporu 3. Ceyrek, 2010. <http://www.gyoder.org.tr>.

International Council of Shopping Centers (ICSC). (2010). ICSC European shopping center awards 2010. <http://www.icsc.org/europeanawards/2010_EuroAwards Winners.pdf>.

Jones Lang LaSalle (2011a)/pulse/Turkey Real Estate Overview-Q1. <http:// www.joneslanglasalle.com.tr/ResearchLevel1/Q1\%202011_JLL_Turkey\%20Real\% 20Estate\%200verview.pdf>.

Jones Lang LaSalle (2011b). On point, Turkey real estate overview: 2010 review and 2011 outlook.

Kalhan, A. (2007). Impact of malls on small shops and hawkers. Economic and political Weekly. (June 2), 2063-2066.

Kompil, M., Celik, H. M. (2006). Analyzing the retail structure change of IzmirTurkey. 42nd ISOCARP Congress.

Lang, T. (2011). Urban resilience and new institutional theory - A happy couple for urban and regional studies. In B. Muller (Ed.), Urban and regional resilience: How do cities and regions deal with change? (pp 15-24). Berlin: Springer-Verlag.

Martin, R. (2012). Regional economic resilience, hysteresis and recessionary shocks. Journal of Economic Geography, 12, 1-32.

Muller, B. (2011). Urban and regional resilience - A new catchword or a consisten concept for research and practice? In B. Muller (Ed.), Urban and regional resilience: How do cities and regions deal with change? (pp 1-14). Berlin: Springer-Verlag.

Multi Corporation (2011). <http://www.multi.eu/index.php?option=com_project \&view=project\&project_id=77>

Ozcan, G. B. (2000). The transformation of Turkish retailing: Survival strategies of small and medium-sized retailers. Journal of Southern Europe and the Balkans, 2(1), 105-120.

Ozuduru, B., Varol, C., Ercoskun Yalciner, O. (in press). Do shopping centers abate the sustainability of shopping streets? The Dilemma in Ankara, Turkey, Cities. <http://www.sciencedirect.com/science/article/pii/S0264275112001801>.

Replacis (2011). Retail Planning for Cities Sustainability, final report.

Resilience Alliance (2007). Urban Resilience. Research Prospectus. A RA initiative for transitioning urban systems towards sustainable futures. <http://www.issuu.com/ getresilient/docs/1172764197_urbanresilienceresearchprospectusv7feb0. SABAH.ENGLISH> 08.06.11.

Simmie, J., \& Martin, R. (2010). The economic resilience of regions: Towards an evolutionary approach. Cambridge Journal of Regions Economy and Society, 3(1), 27-43.

TMMOB-Chamber of Architects (2011). Dosya 22, AVM'ler (special issue on shopping malls).

Tokatli, N., \& ve Boyaci, Y. (1998). The changing retail industry and retail landscapes: The case of post-1980 Turkey. Cities, 15, 345-359. 